\title{
A social work study using factor analysis on detecting important factors creating stress: A case study of hydro-power employees
}

\author{
Batoul Aminjafari $^{\mathrm{a}^{*}}$, Kazem Ghojavand ${ }^{\mathrm{a}}$, Gholamali Iravani ${ }^{\mathrm{b}}$, Mohammad Reza Iravani ${ }^{\mathrm{a}}$ and Daryoush \\ Vakili $^{\mathrm{C}}$
}

\begin{tabular}{|c|c|}
\hline A R T I L E I N F O & A B S T R A C T \\
\hline $\begin{array}{l}\text { Article history: } \\
\text { Received December 15, } 2011 \\
\text { Received in Revised form } \\
\text { February, 14, } 2011 \\
\text { Accepted 24 March } 2012 \\
\text { Available online } \\
\text { March } 292012 \\
\text { Keywords: } \\
\text { Stress } \\
\text { Job satisfaction } \\
\text { Employee performance } \\
\text { Working conditions }\end{array}$ & $\begin{array}{l}\text { The study performs an empirical study based on the implementation of factor analysis to detect } \\
\text { different factors influencing people to have more stress in a hydropower unit located in city of } \\
\text { Esfahan, Iran. The study performed the survey among all } 81 \text { people who were working for } \\
\text { customer service section of this company and consisted of two parts, in the first part; we gather } \\
\text { all private information such as age, gender, education, job experience, etc. through seven } \\
\text { important questions. In the second part of the survey, there were } 66 \text { questions, which included } \\
\text { all the relevant factors impacting employees' stress. Cronbach alpha was calculated as } 0.946 \text {, } \\
\text { which is well above the minimum acceptable level. The implementation of factor analysis has } \\
\text { detected } 16 \text { important groups of factors and each factor is determined by an appropriate name. } \\
\text { The results of our factor analysis show that among different factors, difficulty of working } \\
\text { condition as well as work pressure are two most important factors increasing stress among } \\
\text { employees. }\end{array}$ \\
\hline
\end{tabular}

\section{Introduction}

Stress is one of the most harmful factors, which not only impacts undesirable social relationships among workers in a firm but also it could harm people's health care. There are many conditions where the creation of stress among employees is unavoidable and people must find suitable ways to handle stress, properly. Nevertheless, understanding the nature and root of stress in organizations helps us reduce its impact using appropriate methods (Watson et al., 2011; Çekmecelioğlu \& Günsel, 2011). In fact, for many years, there were significant efforts on learning how it is possible to reduce stress among employees (Bassett et al., 1987; Law et al., 1995).

Gupta and Beehr (1979) studied the relationship between job stress and employee behaviors by investigating the relationship between four job stresses and two employee withdrawal behaviors

\footnotetext{
* Corresponding author. Tel.: +989131036509

E-mail addresses: aminjafari@iaukhsh.ac.ir (B. Aminjafari) 
including absenteeism and turnover. They concluded that prediction of subsequent behaviors was stronger than prediction of prior behaviors, and explained that the predictive power of job stress and background variables taken together was, at least, as powerful as the predictive power of background variables alone.

Smith et al. (1992) studied critical job design elements, which influenced worker stress responses in an electronic monitoring context. The results of their survey indicated that employees who had their performance electronically monitored perceived their working conditions as more stressful, and reported higher levels of job boredom, psychological tension, anxiety, depression, anger, health complaints and fatigue.

Slate and Vogel (1997) performed another study on the perceived atmosphere for participation in correctional decision making and its impact on employee stress and thoughts about quitting. They reported that as employee participation increased, physical and occupational stress decreased.

de Ruyter et al. (2001) performed a survey on the role of stress in call centers in terms of performance or job satisfaction. They explained that specifically the autonomy dimension of empowerment had a role-stress-reducing impact. Interesting substantive direct positive impacts of empowerment competence and leadership consideration on job satisfaction were also considered. Job satisfaction was found to be conducive to job performance. Besides, the study revealed that job satisfaction could reduce turnover intentions, directly or indirectly via organizational commitment.

Vearing and Mak (2007) performed another study on the joint influence of the big five personality factors and an extended model of work stress based on study on effort-reward imbalance (ERI), on employees' depressive symptoms. They explained an association between neuroticism (N) and OVC.

Kim et al. (2009) investigated the moderating roles of organization level and gender in the relationship between job satisfaction and role stress for hotel employees. The study includes measures of job satisfaction, role stress in terms of both conflict and ambiguity and demographic data was implemented to collect information from hotel employees in Republic of Korea. The results indicated that the impact of role stress on job satisfaction is substantially stronger for female employees and supervisory employees than male and non-supervisory workers.

Saastamoinen et al. (2009) examined the own and independent relationships of job strain, workplace bullying, organizational justice and work-home interface with pain. Among women, all psychosocial factors were considered for both acute and chronic pain when adjusted for confounders only. Among men, when adjusted for confounders only, all psychosocial factors were associated with acute and chronic pain, except for family-to-work conflicts among those with acute pain.

Chiang et al. (2010) studied the moderating impacts of job control and work-life balance practices on employee stress in the hotel and catering industry. The results of this survey described that high job demands coupled with low job control and the availability of work-life balance practices leads in a higher level of stress.

Tabatabaei et al. (2011) studied the general health, stress associated to the work and job satisfaction of the Hormozgan Cement Factory employees. The study was semi-experimental with the pre-test and post-test without control group and to improve mental health of employees, psychological trainings and motivational models were executed. The results demonstrated that general health and job satisfaction of employees were higher than average $(\alpha=0.01)$ but their job stress was lower than average $(\alpha=0.01)$. After intervention, results disclosed improvement of job stress and such trainings and models recommended for improvement of employees stress.

Coelho et al. (2011) performed a survey on the mediating impacts of role stress and intrinsic motivation using contextual factors and the creativity of frontline employees. They reported that the 
creativity of frontline service employees is associated positively with role conflict and negatively with role ambiguity.

Costa et al. (2011) performed confirmatory factor analysis of posttraumatic stress symptoms in Brazilian primary care patients using an examination of seven alternative models. Their objective was to study whether the clusters of PTSD symptoms identified in North American and European studies could be replicated in a Brazilian sample composed of 805 primary care patients living in hillside slums. They reported that their results seemed to uphold the cross-cultural validity of the 4-factor, first-order model.

The present study investigates to find out the important factors influencing job stress in one of Iranian hydro facilities. The structure of this study first explains characteristics of all people who participated in our survey.

\section{The proposed study}

The study investigates different factors influencing people to have more stress in a hydropower unit located in city of Esfahan, Iran. Since there were only 81 people working for customer service section of this company and the proposed study tries to focus only on this part of the firm we have decided to distribute questionnaires among all of them. The questionnaire consists of two parts, in the first part, we gather all private information such as age, gender, education, job experience, etc. through seven important questions. In the second part of the survey, there are 52 questions, which include all the important factors influencing employees' stress.

\subsection{Personal characteristics of surveyed people}

As we explained, there are 81 people participated in our survey. In terms of their gender, there were 73 male and 8 female so approximately $90 \%$ of the surveyed people are from man. In terms of their educational background, 10 people had only 9 years of educational background, 48 people finished high school and 23 people had colleague education. While 15 people were single, 66 people were married. In terms of employment type, 21 people were permanent employee, 11 people maintained a five-year contract, 44 people had one-year contract and only 5 employee were on temporary contract.

In terms of job experience, 20 people aged between 20-29, 36 people aged between 30-39, 15 people were between 40 to 49 and finally, 10 employees were over 50 years of age. In terms of job experience, 45 people has from one to ten years of job experience, 15 people had between 11 to 20 years of job experiences and 21 people has between 21 to 30 years of job experience. Finally, 23 people were regular employee, 14 were workers, 30 people were working in customer service and 14 people were hired as accountants.

\subsection{Methodology}

In this survey, we use factor analysis to cluster different factors influencing stress. As usual, we use only factors whose Eigenvalues are greater than one. Therefore, we eliminate any remaining factors with small Eigenvalues. Next, we present details of our 66 questions along with common factors associated with each factor.

\subsection{Questionnaire}

Table 1 shows details of all questions associated with the proposed study of this paper. As we can see there are 66 questions and for each question the common factor is given. 


\section{Table 1}

Details of survey

\begin{tabular}{|c|c|c|}
\hline Q & Title & Common \\
\hline 1 & The feeling that payment does not cover my expenses. & 0.761 \\
\hline 2 & Firm does not pay enough attention to employee's accommodation. & 0.821 \\
\hline 3 & Firm does not pay enough attention to employee's transportation. & 0.703 \\
\hline 4 & There are significant noises in the organization. & 0.766 \\
\hline 5 & Management does not care about job experience. & 0.731 \\
\hline 6 & There are not sufficient equipments. & 0.680 \\
\hline 7 & The employees are not sufficient to be responsive to customers. & 0.806 \\
\hline 8 & Temperature is not properly adjusted. & 0.717 \\
\hline 9 & There is not sufficient visibility. & 0.743 \\
\hline 10 & There is a significant amount of work to do. & 0.831 \\
\hline 11 & There are not supportive entertainment programs. & 0.679 \\
\hline 12 & There is not enough respect towards employees. & 0.772 \\
\hline 13 & There is fear that people may lose their jobs. & 0.747 \\
\hline 14 & There are too much expectations from the workers. & 0.798 \\
\hline 15 & The customers are mostly aggressive. & 0.817 \\
\hline 16 & There is no support for hard working conditions. & 0.718 \\
\hline 17 & There are discriminations among people with various types of employment. & 0.709 \\
\hline 18 & There are discriminations among people with various types of job experiences. & 0.757 \\
\hline 19 & The feeling that employee must always be a good voice of customer. & 0.759 \\
\hline 20 & Special circumstances of work place. & 0.750 \\
\hline 21 & There is not over pay for overtime work. & 0.848 \\
\hline 22 & There is not enough time to finish all works on time. & 0.712 \\
\hline 23 & Displacement of employees happens without asking the opinions of employees. & 0.743 \\
\hline 24 & Management always looks for shortcoming and do not pay to other issues. & 0.792 \\
\hline 25 & There are not enough hardware and software packages. & 0.777 \\
\hline 26 & The people with more job experience work less. & 0.840 \\
\hline 27 & The people with less job experience work less. & 0.778 \\
\hline 28 & The employees are not participated in decision-making procedures. & 0.857 \\
\hline 29 & Promotion policy is not good. & 0.737 \\
\hline 30 & There is no trust among employees. & 0.756 \\
\hline 31 & Connections work better than regulations. & 0.835 \\
\hline 32 & Customers' complaints play important role. & 0.850 \\
\hline 33 & Work duties are not clear for employees. & 0.796 \\
\hline 34 & The management is making their decision selectively. & 0.754 \\
\hline 35 & Limited number of employees performs a significant amount of work. & 0.681 \\
\hline 36 & It is not possible to go to vacations. & 0.801 \\
\hline 37 & Management does not care about employees' living and personal affairs. & 0.869 \\
\hline 38 & The loans are sufficient. & 0.770 \\
\hline 39 & There is poor management system. & 0.742 \\
\hline 40 & All other problems are transferred to customers. & 0.742 \\
\hline 41 & The rules and regulations have some flaws. & 0.835 \\
\hline 42 & There is no promotion or punishment plan. & 0.761 \\
\hline 43 & The working condition is boring. & 0.835 \\
\hline 44 & Overtime work is insufficient. & 0.717 \\
\hline 45 & The feedbacks from experienced people are not used. & 0.835 \\
\hline 46 & There are extra job replacements. & 0.689 \\
\hline 47 & There are just too much expectations from top management. & 0.730 \\
\hline 48 & Employees are not sufficiently aware of the rules and regulations. & 0.782 \\
\hline 49 & There are just too much attentions on degrees instead of experiences. & 0.764 \\
\hline 50 & There is just too much discrimination among employees. & 0.696 \\
\hline 51 & Stresses are transferred from other sections to employees. & 0.739 \\
\hline 52 & There is just too much attention to customer care. & 0.784 \\
\hline 53 & There is fear on making mistake due to high volume of work. & 0.824 \\
\hline 54 & There are several issues associated with rate of charges. & 0.724 \\
\hline 55 & There are eavesdropping among some employees. & 0.745 \\
\hline 56 & Employees cannot use their vocational events due to high volume work. & 0.786 \\
\hline 57 & There are just too much unreachable deadlines. & 0.843 \\
\hline 58 & Employees are not feeling good for outsourcing activities. & 0.682 \\
\hline 59 & The works are not performed properly. & 0.754 \\
\hline 60 & Employees are asked to perform works while they are qualified for. & 0.794 \\
\hline 61 & Works are not assigned fairly among employees. & 0.773 \\
\hline 62 & There is no justice for giving awards. & 0.702 \\
\hline 63 & There is no replacement for employees when some go on vacation. & 0.816 \\
\hline 64 & There is no friendship relationship among employees. & 0.727 \\
\hline 65 & There is feedback for customers' complaints. & 0.726 \\
\hline 66 & Customers are not aware of rates and regulations. & 0.719 \\
\hline
\end{tabular}


From the results of Table 1, we can observe that the common factors for 66 questions of stressful factors are distributed from 0.679 to 0.857 . Questions $6(0.680), 11(0.679), 35(0.681), 37(0.689)$, 46(0.689), 50 (0.696) and 58 ( 0.682) maintained the lowest common factor. On the other hand, questions 2 (0.821), 7 (0.806), 10 (0.831), 15 (0.817), 21 (0.848), 26 (0.840), 28 (0.857), 31 (0.835), 32 (0.850), 36 (0.801), 41(0.835), 43 (0.835), 45(0.835), 54(0.824), 57 (0.843), 63 (0.816) maintain the highest common factors. Next, we present details of our factor analysis.

\section{Factor analysis}

Table 2

The results of principal component analysis (PCA)

\begin{tabular}{ccccccc}
\hline \multirow{2}{*}{ Component } & \multicolumn{3}{c}{ Initial Eigenvalues } & \multicolumn{2}{c}{ Extraction Sums of Squared Loadings } \\
\cline { 2 - 7 } & Total & Percent & Cumulative & Total & Percent & Cumulative \\
\hline 1 & 18.769 & 28.438 & 28.438 & 6.454 & 9.779 & 9.779 \\
2 & 5.044 & 7.643 & 36.081 & 5.791 & 8.744 & 18.553 \\
3 & 4.041 & 6.123 & 42.204 & 5.527 & 8.375 & 26.928 \\
4 & 2.843 & 4.294 & 46.498 & 4.156 & 6.297 & 33.225 \\
5 & 2.496 & 3.781 & 50.280 & 3.333 & 5.050 & 38.274 \\
6 & 2.274 & 3.446 & 53.726 & 2.964 & 4.492 & 42.766 \\
7 & 1.919 & 2.907 & 56.633 & 2.804 & 4.249 & 47.015 \\
8 & 1.842 & 2.791 & 59.423 & 2.749 & 4.165 & 51.180 \\
9 & 1.762 & 2.670 & 62.093 & 2.676 & 4.055 & 55.235 \\
10 & 1.636 & 2.479 & 64.573 & 2.277 & 3.450 & 58.685 \\
11 & 1.470 & 2.227 & 66.80 & 2.252 & 3.412 & 62.068 \\
12 & 1.453 & 2.201 & 69.001 & 2.180 & 3.303 & 65.401 \\
13 & 1.350 & 2.046 & 71.047 & 2.075 & 3.143 & 68.544 \\
14 & 1.199 & 1.817 & 72.864 & 1.773 & 2.687 & 71.231 \\
15 & 1.176 & 1.782 & 74.646 & 1.734 & 2.627 & 73.857 \\
\hline
\end{tabular}

As we can observe from the results of Table 2, 16 factors maintain high Eignevalues and they are shown in terms of non-increasing order. The first factor, which is the organizational and job related factor with the biggest Eigenvalue, 18.769 , represents $28.438 \%$ of the total variance of stressful factors. In summary, 16 factors represent $72.286 \%$ of total variance of stressful factors.

\subsection{First factor: Stress posed by hard job conditions}

This factor includes eight items 10 (0.643), 16 (0.507), 22 (0.538), 34(0.420), 35 (0.712), 57 (0.649), $60(0.762)$ and $63(0.753)$ and based on what we observe from the related questions we nominate this factor as stress posed by hard job conditions.

\subsection{Second factor: Stress posed by customers}

The second factor includes six items of 14 (0.701), $15(0.675), 25(0.732), 32(0.769), 52(0.718)$ and 66 (603). Based on the question we call this factor as stress posed by customers.

\subsection{Third factor: Stress posed by managers and colleagues}

This factor includes only five items including 39 (0.678), 45 (0.877), 48 (0.804), $61(0.478)$ and 62 (0472) and we can conclude that this factor represents stress posed by managers and colleagues.

\subsection{Fourth factor: Lack of a good cooperation}

This factor consists of 6 items including 23 (0.540), 26 (0.60), $27(0.827), 28(0.689), 30(0.475)$ and 55 (0.589), which represent the lack of a good cooperation among workers. 
3.5 Fifth factor: Stress posed by discrimination

Discrimination is an important factor coming from items 2 (0.789), 5 (0.640), $11(0.489)$ and 17 (0.452).

3.6 Sixth factor: Stress posed by unsuitable rules and regulations

This item is another important factor, which includes item $8(0.612), 9(0.750), 36(0.556)$ and 37 (0.435).

3.7 Seventh factor: Stress posed by boring operations high expectations

When there is no change on work and workers are expected highly they may feel stress and this is recognized by item 19 (0.585), 21 (0.537) and $43(0.796)$.

3.8 Eighth factor: Stress posed by blaming for no good reason

This item is another important factor, which includes only item 24 (0.792) and we call it blaming for no good reason.

3.9 Ninth factor: Stress created by pressure posed from various divisions and lack of good human relationships

This item is another important factor, which includes four items, which are $12(0.450), 38(0.777)$ and $40(0.482)$ and we call it stress created by pressure posed from various divisions and lack of good human relationships.

\subsection{Tenth factor: Stress posed by lack of job security}

This factor is detected within two factors of $13(0.603)$ and $58(0.761)$, which implies that job security plays an important role on stress.

\subsection{Eleventh factor: Stress posed by lack of good outlook for job}

This factor is detected within two factors of 29 (0.448) and 44 (0.613), which implies that a good outlook for job can reduce the bad impact of stress.

3.12 Twelfth factor: Stress posed by too much job exchange and lack of a good performance measurement

This factor is determined within two factors of $46(0.729)$ and $65(0.648)$, which implies that the lack of a performance measurement could increase stress among workers.

3.13 Thirteenth factor: Stress posed by lack of a good regulation for tasks

This item is another important factor, which includes only item $59(0.650)$, which represents for lack of a good regulation for tasks assigned to workers.

3.14 Fourteenth factor: Stress posed by the fear of arriving on time

This factor is determined within two factors of $3(0.805)$ and $53(0.455)$, which implies that workers may feel bad for being late at work.

3.15 Fifteenth factor: Stress posed by lack of a good perception of job

This item is another important factor, which includes only item 33 (0.687), which represents for lack of a good perception for tasks assigned to workers. 


\subsection{Sixteenth factor: Stress posed by job location}

This item is another important factor, which includes only item $20(0.666)$, which is associated with job location.

In summary, the results of Factor analysis using principal component analysis can help us detect all important issues creating stress among workers.

\section{Conclusion}

In this paper, we have presented an empirical study to investigate different factors influencing people to have more stress in a hydropower unit located in city of Esfahan, Iran. Since there were only 81 people working for customer service section of this company and the proposed study tries to focus only on this part of the firm we have decided to distribute questionnaires among all of them. The results of our factor analysis indicated that among different factors, difficulty of working condition as well as work pressure are two most important factors increasing stress among employees.

\section{Acknowledgment}

The authors would like to thank the officials of hydropower who helped us finish this work, completely.

\section{References}

Bassett, J.R., Marshall, P.M., \& Spillane, R. (1987). The physiological measurement of acute stress (public speaking) in bank employees. International Journal of Psychophysiology, 5(4), 265-273

Chiang, F.F.T., Birtch, T.A., \& Kwong Kwan, H. (2010). The moderating roles of job control and work-life balance practices on employee stress in the hotel and catering industry. International Journal of Hospitality Management, 29(1), 25-32.

Coelho, F., Augusto, M., \& Lages, L.F. (2011). Contextual factors and the creativity of frontline employees: The mediating effects of role stress and intrinsic motivation. Journal of Retailing, 87(1), 31-45.

Çekmecelioğlu, H.G., \& Günsel, A. (2011). Promoting creativity among employees of mature industries: The Effects Of Autonomy And Role Stress On Creative Behaviors And Job Performance. Procedia - Social and Behavioral Sciences, 24, 889-895.

Costa, M.F., Mendlowicz, M.V., Vasconcelos, A.G.G., Berger, W., da Luz, M.P., Figueira, I., Rosa, M.L.G. (2011). Confirmatory factor analysis of posttraumatic stress symptoms in Brazilian primary care patients: An examination of seven alternative models. Journal of Anxiety Disorders, 25(7), 950-963

de Ruyter, k., Wetzels, M., \& Feinberg, R. (2001). Role stress in call centers: Its effects on employee performance and satisfaction. Journal of Interactive Marketing, 15(2), 23-35.

Gupta, N., \& Beehr, T.A. (1979). Job stress and employee behaviors. Organizational Behavior and Human Performance, 23(3), 373-387.

Kim, B.P., Murrmann, S.K., \& Lee, G. (2009). Moderating effects of gender and organizational level between role stress and job satisfaction among hotel employees. International Journal of Hospitality Management, 28(4), 612-619.

Law, J., Pearce, P.L., \& Woods, B.A. (1995). Stress and coping in tourist attraction employees. Tourism Management, 16(4), 277-284.

Slate, R.N., \& Vogel, R.E. (1997). Participative management and correctional personnel: A study of the perceived atmosphere for participation in correctional decision making and its impact on employee stress and thoughts about quitting. Journal of Criminal Justice, 25(5), 397-408. 
Smith, M.J., Carayon, P., Sanders, K.J., Lim, S-Y., \& LeGrande, D. (1992). Employee stress and health complaints in jobs with and without electronic performance monitoring. Applied Ergonomics, 23(1), 17-27.

Saastamoinen, P., Laaksonen, M., Leino-Arjas, P., \& Lahelma, E. (2009). Psychosocial risk factors of pain among employees. European Journal of Pain, 13(1), 102-108.

Tabatabaei, S., Hosseinian, S., \& Gharanjiki, B. (2011). General Health, Stress Associated to the Work and Job Satisfaction of Hormozgan Cement Factory Employees in Iran. Procedia - Social and Behavioral Sciences, 30, 1897-1901.

Vearing, A., \& Mak, A. S. (2007). Big five personality and effort-reward imbalance factors in employees' depressive symptoms. Personality and Individual Differences, 43(7), 1744-1755.

Watson, R., Yanhua, C., Ip, M.Y.K., Smith, G.D., Wong, T.K.S., \& Deary, I.J. (2012). The structure of stress: Confirmatory factor analysis of a Chinese version of the stressors in Nursing Students Scale (SINS). Nurse Education Today, In Press. 